\title{
Optimal multimedia combination for students with dyslexia
}

\author{
Maja Lebeničnik ${ }^{\mathrm{a}}$, Ian Pitt ${ }^{\mathrm{b}}$, Andreja Istenič Starčičč,c,d,* \\ ${ }^{a}$ University of Primorska, Faculty of Education, Koper, Slovenia \\ ${ }^{b}$ University College Cork, School of Computer Science \& Information Technology, Cork, Ireland \\ ${ }^{c}$ University of Ljubljana, Faculty of Civil and Geodetic Engineering, Ljubljana, Slovenia \\ ${ }^{d}$ Kazan Federal University, Institute of Psychology and Education, Kazan, Russia
}

\begin{abstract}
Many contemporary online learning resources use more than one sensory modality (audio, visual) or presentation mode (pictures, text). Multimedia learning material is often recommended for and adopted by students with dyslexia. However, there are not many empirical studies that support the benefits of multimedia for this group. Due to the variety of difficulties that these students may experience, multimedia may not be the most appropriate type of online content for them. Our study aimed to identify the most appropriate combination of multimedia content for them from among three commonly-used types of online learning resources. An experiment was conducted in which 27 students with dyslexia learned about a topic under one of three conditions: a scroll-down website with onscreen text and static pictures, video lecture and subtitled video lecture. No significant differences in learning outcomes were found between the groups. However, the effect sizes indicated the superiority of the website over the other two conditions. Because of the small sample size, further research is needed.
\end{abstract}

\section{Introduction}

Today's ICT allows for easier and faster designing and uploading of multimedia digital material, which has resulted in a growing amount of multimedia content on the Web. The expression 'multimedia' may refer to information as combinations of different presentation modes (e.g., verbal or pictorial information) or sensory modalities (e.g., acoustic and visual information) (Mayer, 2009). The use of multimedia online learning materials, including video lectures, is widespread in higher education. However, only a few studies have explored optimal combinations of conditions and impact on learning for diverse student groups (Colliot and Jamet, 2018). The Cognitive Theory of Multimedia Learning (CTML) (Mayer, 2009) is a theory that is widely used as the theoretical background for research into learning in computer-based and online multimedia environments. One of the central premises of the CTML is that for mainstream students, the use of both words and pictures fosters deeper learning than learning from verbal material only (Mayer, 2003, 2009). Audio or

\footnotetext{
${ }^{*}$ Corresponding author

Email addresses: maja.lebenicnik@pef .upr.si (Maja Lebeničnik), i.pitt@cs.ucc.ie (Ian Pitt), andreja.starcic@gmail. com (Andreja Istenič Starčič)
} 
multimedia information is also presented in the literature as better alternatives to on-screen text for students with dyslexia (Bell, 2009; Santana, de Oliveira, Anhol Almeida and Calani Baranauskas, 2012); however the most appropriate type of multimedia learning content for students with dyslexia remains unclear. The study by Alty, Al-Sharah and Beacham (2006) showed that students with dyslexia have problems when learning from digital multimedia material. The development of universally-designed online content, which can be perceived and understood equally by people with and without disabilities, is among the most essential demands of contemporary society. The legislation mandating accessibility of learning technologies and content aims to remove the risk of students being disadvantaged in their studies (Kumar and Owston, 2016).

The study presented here aimed to determine the most appropriate type of digital multimedia learning material for students with dyslexia. An experimental study was conducted to determine which type of multimedia online learning resource (website, video lecture, or subtitled video lecture) produces the best learning outcome for students with dyslexia.

\subsection{Cognitive theory of multimedia learning}

The Cognitive Theory of Multimedia Learning (CTML) (Mayer, 2009) is one of the most influential cognitive theories regarding multimedia learning. According to the CTML, human cognitive architecture consists of two distinct information-processing channels where different types of information are processed. Visual information (e.g., pictures, animations, videos) is mainly processed in the visual/pictorial channel, and auditory information (e.g., narration) is mainly processed in the auditory/verbal channel. Once that information is transferred from sensory to working memory, it may be converted from one channel to the other if the learner actively constructs a mental model that differs in nature (verbal versus pictorial) than the incoming information. One such example is the onscreen text. It is initially processed in the visual/pictorial channel, but later, when entering the working memory, it is assumed to be processed in the auditory/verbal channel. CTML identifies the limited cognitive capacity of each channel as the main obstacle for effective multimedia learning. On the basis of the CTML, Mayer (2009) developed 12 principles for designing effective multimedia instructional material that are aimed at reducing non-relevant cognitive load. These principles have been extensively researched through empirical studies over the last two decades (Sorden, 2013). Some principles have strong empirical support, however, as the author of the theory has pointed out, the validity of each principle is limited and further research into these limitations is needed (Mayer, 2009). Further we describe two principles, most relevant for our paper.

The Modality principle states that people learn better from graphics and narration than from graphics and printed text (Mayer, 2009). The modality principle was empirically confirmed in many experiments over a variety of learning situations (review in Mayer, 2009) and in a meta-analysis (Ginns, 2005; Reinwein, 2012). Studies suggest that the modality principle is stronger for complex material, shorter text, and dynamic material (Reinwein, 2012). The modality effect disappears, or in some cases reverse-modality effect appears when the learner has control over the pace of the presentation (Ginns, 2005; Reinwein, 2012; Tabbers, Martens and van Merrienboer, 2004) or when the text is long (Wong, Leahy, Marcus and Sweller, 2012). Differences in the modality effect are also related to the type of graphics. For example, She and Chen (2009) found that the modality effect is valid for animation, but not for simulation.

Several authors suggest that the modality effect is due to restrictions in the sensory rather than the working memory, as proposed in CTML (Rummer, Scweppe, Fürstenberg, Scheiter, 
and Zindler, 2011; Wong et al., 2012). The explanation of the modality principle in CTML is often criticised because Mayer claims that his theory is in accordance with Baddeley's model of the working memory. However, some scholars claim that according to Baddeley's model, all verbal information (written or spoken) is processed in the verbal part of the working memory, that is a phonological loop, so the processing of written text should not interfere with the processing of the picture part of multimedia material (Gyselinck, Jamet and Dubois, 2008; Tabbers, 2002; in Reinwein, 2012).

According to the redundancy principle, a combination of written text, spoken text, and a picture is less efficient than a combination of spoken words and picture (Mayer, 2009). Written text in this condition is extraneous information, as the visual/pictorial channel is already busy processing the picture. This principle is questionable for specific users. For example, subtitles are available for many videos, and this has obvious benefits for those who are deaf or hard of hearing, second language learners, or anyone experiencing poor-quality audio reception. The redundancy principle is less applicable when captions are shortened when spoken text is presented before the written text, and when there are no graphics (Mayer, 2009). Indeed, studies show limited validity of the redundancy principle. Liu, Lai and Chuang (2011) showed that presenting both onscreen and narrative text next to a picture, in fact, caused a redundant effect because the students reported higher cognitive load. However, on recording the students' eye movements, it was found that they were able to filter out redundant information (Liu et al., 2011). Knoop-van Campen, Segers and Verhoeven (2019) discovered that for typically-developing children, a reverse redundancy effect emerged while learning from multimedia presentation.

One group for which the validity of the CTML principles still needs further research is students with dyslexia. Greer, Crutchfield and Woods (2013) indicated that further studies must be carried out to determine whether the CTML principles (e.g., the modality and redundancy principles) are relevant for students with dyslexia because of the limitations in their working memory.

\subsection{Students with dyslexia and accessibility of multimedia content}

The number of students with learning difficulties entering tertiary education has increased in recent years. 'Learning disabilities' refers to problems in acquiring knowledge to the level expected of those of the same age (Abd Ghani and Gathercole, 2013). Dyslexia is one of the most common special educational needs reported in the higher education environment (Vrhovski, 2007). It is estimated that 5\% of the population has dyslexia, and it occurs more often in the male than in the female population (Thambirajah, 2010). 'Dyslexia is a learning difficulty that primarily affects the skills involved in accurate and fluent word reading and spelling' (Rose, 2009, pp.9). People with dyslexia have extreme difficulties with word recognition, spelling, and decoding, which consequently affect their reading comprehension, reading fluency, and reading experience (Thambirajah, 2010). Dyslexia can lead to reduced vocabulary (Webster, 2016). Thambirajah (2010) states that people with dyslexia show difficulties only in reading words and not with grammar, meaning, and social use of language. There are a few theories explaining dyslexia, but the most established one is the theory of core phonological deficit. It suggests that dyslexia (especially difficulties with single-word reading) is caused by impaired abilities of phonological awareness (segmenting spoken words into phonemes) and connecting written letters with sound (Thambirajah, 2010). Dyslexia is connected to weaknesses in the working memory, especially verbal working memory (phonological loop) and central executive (Abd Ghani and Gathercole, 2013; Thambirajah, 2010). Besides cognitive deficits, some people with dyslexia show a variety of 
other problems related to sensory (visual and auditory processing) and motor skills. However, it is still not understood why this occurs (Ramus, Rosen, Dakin, Day, Castellote, White and Frith, 2003). Different individuals with dyslexia show different patterns of difficulties, and there exist theories about several subtypes of dyslexia (Vellutino et al., 2004). Higher education requires extensive reading (academically), writing, and use of a complex vocabulary (Webster, 2016). In the higher education setting, students with dyslexia face a variety of problems and may experience difficulties such as those listed below (Abd Ghani and Gathercole, 2013; Beacham and Alty, 2006; Boyle, 2012; Draffan, 2002; Olofsson, Ahl and Taube, 2012):

- Reading difficulties

- Spelling and writing difficulties

- Difficulties with understanding and recognizing written and spoken words

- Memory difficulties, such as remembering sequences of items, needing information to be repeated

- Challenges in applying study skills, such as identifying key ideas in a text, note-taking during lectures and organisational skills.

The diversity of users with dyslexia is reflected in the diversity of accessibility needs among users (Björklund, 2011). If people cannot properly perceive or understand online content, it becomes irrelevant to them and represents a barrier to their use of the web, contributing to the digital divide (Cullen, 2001). 'Web accessibility means that the Web is designed so that people with disabilities can perceive, understand, navigate, and interact with it effectively, as well as create and contribute content to the Web' (Web Accessibility Initiative, 2005). Accessible online content for students with dyslexia is online content (e.g., website, tools) in which navigation is easy, textual presentation is adequate, the content is distraction-free, language is not too complex, and alternative forms of information besides written/printed words are presented (Bell, 2009; McCarthy and Swierenga, 2010; Santana et al., 2012). Students with dyslexia benefit from websites that have a clear layout, with information broken up into chunks and presented in columns (Bell, 2009). On complex websites, clear navigation mechanisms such as breadcrumb trails, index pages, site maps, internal search, links, visual clues, and lists of content are crucial (Santana et al., 2012). Textual information that has to be read causes the most difficulties for users with dyslexia. In relation to that, recommended solutions include the use of larger text sizes, sans-serif fonts, stationary text, backgrounds in pastel colours, highlighting of relevant information, and features allowing users to customise websites (Bell, 2009; Santana et al., 2012). Long passages of text without images are also problematic (Web Accessibility Initiative, 2017). Complex sentences and words, long paragraphs, and the use of the passive voice and double negatives are not consistent with the demand for plain language (McCarthy and Swierenga, 2010; Santana et al., 2012). Some students with dyslexia use screen readers, so online resources need to be compatible with screen readers. Non-textual forms of information, such as images, videos, and audio files are also recommended for students with dyslexia. They learn more effectively when a material is in visual form (Reid, Strnadova and Cumming, 2013). Webster (2016) also found that students with dyslexia prefer visual learning content, such as videos and diagrams. From the accessibility point of view, images must function to complement textual information and also serve to divide textual information into pieces. 
However, including pictures just for decorative purposes is not recommended. Additionally, images should not be too small. Moving and blinking images are also perceived as a distraction. In relation to video and audio files, the content should not include unnecessary sounds and music and not be set to autoplay to avoid distracting users with dyslexia.

\subsection{Multimedia learning and students with dyslexia}

Because they have problems with reading, it might be expected that onscreen textual information would be less appropriate for students with dyslexia, and the literature suggests that using audio or multimedia would be better alternatives (Bell, 2009; Santana et al., 2012). Multisensory learning is also recommended for students with dyslexia (Bell, 2009; Draffan, 2002). Reid et al. (2013) state that the multisensory approach involves auditory, visual, kinaesthetic, and tactile information. However, empirical data suggests that multimodality can cause extra difficulties in learning for this group. Alty et al. (2006) found that using media in combination (voice and graphics, written text and graphics) reduced the effectiveness of learning materials for students with dyslexia. A text-only condition proved best, followed by a combination of written text and graphics, while the narration and graphics condition produced the worst results. There are also inconclusive results regarding the validity of the modality and redundancy principles for students with dyslexia.

In the experiment by Alty et al. (2008), this principle was found to be valid for mainstream students but not for students with dyslexia. Similarly, Wang et al. (2018) discovered a reversed modality effect for recall and recognition test results. On the contrary, Knoop-van Campen et al. (2019) discovered the modality effect was stronger for transfer knowledge in a group of children with dyslexia than their peers.

Learning from video, which encompasses visual content as well as audio content, may be seen as multimedia content in accordance with the modality principle. From previous literature regarding the effectiveness of video material for students with dyslexia, it has been established that video material needs to be self-paced in order to be accessible for students with dyslexia (Bell, 2009). Students with dyslexia express a preference for video materials (Webster, 2016) and are among the most frequent users of video lectures (Leadbeater, Shuttleworth, Couperthawaite and Nightingale, 2013). Students with dyslexia prefer dynamic animations over static pictures but to a lesser extent than mainstream students (Taylor, Duffy and Hughes, 2007). A large proportion of students using video lectures are students with dyslexia (Mortimore and Crozier, 2006). Some papers suggest that the use of video material (asynchronous video feedback) is connected to an overall positive experience in learning (McDowell and Catterall, 2014). Video lectures were found to be more effective for learning than audio recordings of lectures for students with dyslexia (Giardi, 2016).

The Redundancy principle of CTML states that if the same information is provided through two different media, it decreases learning efficacy (Mayer, 2009). Whether or not this is valid for students with dyslexia is still not known. On the one hand, text-to-speech software and screen readers (which allow Graphical User Interfaces to be navigated using speech) are recommended for students with dyslexia (Draffan, 2002). Ruedas-Rama and Orte (2012) also report that normally-achieving higher education students expressed positive opinions about having audio and written digital learning information presented simultaneously. Presenting sound and text together can be compared to phonological training, which is described as useful for people with dyslexia (Björklund, 2011).

\subsection{Research hypotheses}

In this study, the main aim is to examine how effectively students with dyslexia learn from three common multimedia online learning resources: website, video lecture, and sub- 
titled video lecture. We found several studies related to this problem, but those involved other types of pictorial information, rather than video lectures. Video lectures are currently an important type of online learning resources for informal learning and are also used at many universities to support the formal learning process. Additionally, we will examine the possible benefits of subtitled video lectures. To our knowledge, this aspect has never been tested experimentally before. Subtitles and captions are already available for much online video content, so discovering the possible benefits would also have a practical value.

With measuring learning outcomes in three conditions, we measure the effectiveness of three learning conditions as well as test the validity of the modality and redundancy principles for students with dyslexia.

We set the following hypotheses:

H1: Students with dyslexia will have better learning outcomes under the video with subtitles condition (experimental group 2) and the video with no subtitles condition (experimental group 1) than under the website condition (control group).

All three conditions involved the use of multimedia material with the inclusion of verbal and pictorial information. We assume that the two video conditions will be superior to the website condition because of the evident difficulties of people with dyslexia with reading. Studies also show that students with dyslexia show a preference for video material (Webster, 2016) and are frequent users of video lectures (Leadbeater et al., 2013).

H2: Students with dyslexia will have better learning outcomes under the video with subtitles condition (experimental group 2) than under the video with no subtitles condition (experimental group 1).

Since no previous studies have been found involving students with dyslexia using subtitles, our assumption that video lectures with subtitles will be the more efficient condition is based on the fact that for students with dyslexia, assistive technology that supports the simultaneous presentation of written and spoken words (text-to-speech) is recommended (Draffan, 2002). Further, phonological training, an intervention for dyslexia, also presents sound and text together (Björklund, 2011). However, on the other hand, redundant verbal information (in spoken and written form) may overload students' working memory, especially the phonological part, which is impaired in students with dyslexia. Also CTML identifies this as an undesirable condition because it heightens the extraneous cognitive load (Mayer, 2009).

H3: Students with dyslexia will have better learning outcomes under the video with no subtitles condition (experimental group 1) than under the website condition (control group).

We predict that video lectures will be more beneficial than the website, which includes static text and pictures, because it is consistent with the modality principle (Mayer, 2009). The video lecture includes audio information as well as static pictures which are identical to those on the website. She and Chen (2009) discovered that the modality principle is valid for animations, which are similar to video lectures, regarding their interaction mode. A previous study (Alty et al., 2006) discovered that learning simultaneously with narration and graphics resulted in worse learning outcomes for students with dyslexia. However, we expect this condition will not be the worst in our case because students will be able to self-pace the material. Self-pacing is often highlighted concerning video usage by people with dyslexia (Bell, 2009).

H4: Students with dyslexia will have better learning outcomes under the video with subtitles condition (experimental group 2) than the website condition (control group).

We assume students with dyslexia will learn better from a video with subtitles than from a website because, as explained before, we expect (1) the video format to be more accessible 
than the text-based format for students with dyslexia and (2) video lectures with subtitles encompass a multisensory approach, which is recommended for students with dyslexia.

\section{Methodology}

\subsection{Research design and experimental factors}

We conducted a quantitative experimental study using descriptive and causal experimental methods. Participants were asked to undertake a learning task concerning the use of cookies on websites. The learning material was presented either as a website with text and static pictures (control condition), as a video lecture (experimental condition 1), or as a video lecture with sub-titles (experimental condition 2). Participants were tested on their knowledge of the topic before and after undertaking the learning task. A between-subjects design was used. Because of a very small sample, strictly random assignment to groups might have resulted in non-equal groups on the variable of gender. Matching was performed to equate the control and experimental groups on the variable of gender. Each male participant was matched with two female participants. Then three matched participants were randomly assigned to the comparison groups.

In the control group, the learning material was presented as a scroll-down website with on-screen text and static pictures. This can be considered a standard intervention for two reasons:

- Textual information is the most commonly used type of online learning content (Ravanelli and Serina, 2014).

- Text-only material was considered the best condition for students with dyslexia (Alty et al., 2006).

Because the control group used static learning material and the experimental groups used transient learning material, we applied several steps to ensure the static/dynamic component would not affect outcome measures:

- Participants in all groups had an equal amount of time available for learning.

- Participants in the control group could re-read material, and participants in the experimental groups could pause, replay, rewind, and forward the learning material.

\subsection{Participants}

In all, $27 \mathrm{HE}$ students with dyslexia voluntarily participated in the study. We used a convenience sample. We recruited participants through the Disability Support Service at University College Cork (UCC). Thus all our participants met the criteria used by UCC to identify students with dyslexia in need of support. The sample was a non-randomised purposeful sample because we intentionally included only students with dyslexia who had agreed to participate in the study. In our study, there were $12(44.4 \%)$ male and $15(55.6 \%)$ female participants enrolled in different study programmes and study levels at University College Cork. Regarding their study field, $5(18.5 \%)$ students were from arts and humanities, $11(40.7 \%)$ from Science and Technology, 3 (11.1\%) from social sciences, and $8(29.6 \%)$ from other study fields. We did not invite IT students to participate in the study because of their expected prior knowledge on the topic of the learning material. The participants' age varied between 19 and 33 years, with the average age being 22.6 years $(\mathrm{SD}=4.43)$. 


\subsection{Material}

Three types of learning materials were developed to present information on the topic of web cookies. The materials included a description of the concept of web cookies, underlying mechanisms of how cookies operate, and instructions on how to set browser options to control the use of cookies. In the control condition, the learning material was presented on a scroll-down website. On the website, the text was presented on the left side and pictures presented at the right side of the screen. Four static pictures were included in the material. The first picture was of decorative nature, the second was a graphical presentation of the process of how cookies operate, and last two images were screenshots, showing browser settings. Under experimental condition 1, the material was presented as a video of a native-English speaking lecturer speaking about the topic. The static pictures that accompanied the spoken text were presented on the right side of the screen at appropriate times. Under experimental condition 2, the material was presented in the same form as under experimental condition 1 with subtitles of the spoken text added on the bottom of the screen. In both cases, the video was 9 minutes long. The textual information was identical under all conditions, but the size and font of the text differed when presented as a part of the website and as subtitles in the video condition. The same static pictures were used under all three conditions.

\subsection{Instruments}

Pre- and post-test: We developed two electronic versions of a knowledge test. The first version was applied as a pre-test and the second version as a post-test. The same multiplechoice questions were applied in both versions. However, the order of the questions, as well as the order of given possible answers, were different in the pre- and post-test to minimise the possibility of memorisation. Participants also did not receive any feedback on their performance in the pre-test. Approximately 20 minutes passed between finishing the pretest and starting the post-test. Each question had one correct answer. A correct answer was given 1 point, while an incorrect or missing answer was given 0 points. The test scores on pre- and post-test for each participant were calculated by summing their correct answers on 17 questions. Questions were piloted on 4 students with dyslexia. As seen in Table 1, 14 questions measured retention and 3 questions measured the transfer of knowledge. In Table 1, one can see the number of given choices for each question. The design of the test was in accordance with accessibility recommendations for dyslexia, posting only one question per page with onscreen text that was presented on a yellow surface. The pre-test questionnaire included, besides the pre-knowledge test, demographic items of gender, age, and study programme. One question addressed participants' previous experience regarding the management of cookies. The item was 'How much do you agree with the following statement? I know how to manage cookies on the computer - Please circle a number ( 1 Not agree at all; 5 - Completely agree).' Table 1 shows the difficulty index for each item in the pre-test as well as the corresponding item in the post-test. The difficulty index is the percentage of examinees that correctly answered the question (Sočan, 2011). 12 questions out of 17 gained a higher proportion of correct answers after completing of the learning task. All, except question number 3 in the pre-test and 3 questions $(10,12$ and 15) in the post-test, had difficulty indexes in recommended limits of 0.10-0.90 (Sočan, 2011).

The reliability and construct validity of our test were difficult to precisely assess because our sample was tiny. The most common method to establish the reliability of the measures is to calculate Cronbach's alpha $(\alpha)$. However, according to Yurdugül (2008), extremely small samples $(N<30)$ are not appropriate for calculating Cronbach's alpha $(\alpha)$. The reliability of the pre-test and post-test in our case was measured with a split-half method. This formula 
Table 1: Characteristics and item difficulty indexes for pretest and posttest questions

\begin{tabular}{crcrcc}
\hline $\begin{array}{c}\text { Question } \\
\text { number }\end{array}$ & IDI & $\begin{array}{c}\text { Question } \\
\text { number }\end{array}$ & IDI & $\begin{array}{c}\text { Number of } \\
\text { given answers }\end{array}$ & $\begin{array}{c}\text { Type of } \\
\text { knowledge }\end{array}$ \\
\hline 1 & 40.74 & 4 & 62.96 & 4 & Retention \\
2 & 11.11 & 3 & 66.67 & 3 & Retention \\
3 & 7.41 & 6 & 29.63 & 3 & Retention \\
4 & 51.85 & 9 & 74.07 & 4 & Retention \\
5 & 29.63 & 1 & 40.74 & 4 & Retention \\
6 & 74.07 & 5 & 88.89 & 3 & Retention \\
7 & 37.04 & 7 & 55.56 & 3 & Retention \\
8 & 66.67 & 10 & 100.00 & 3 & Transfer \\
9 & 25.93 & 8 & 11.11 & 4 & Transfer \\
10 & 48.15 & 2 & 33.33 & 3 & Transfer \\
11 & 62.96 & 11 & 55.56 & 2 & Retention \\
12 & 37.04 & 13 & 55.56 & 2 & Retention \\
13 & 25.93 & 17 & 22.22 & 2 & Retention \\
14 & 77.78 & 12 & 100.00 & 2 & Retention \\
15 & 81.48 & 14 & 77.78 & 2 & Retention \\
16 & 33.33 & 15 & 92.59 & 2 & Retention \\
17 & 44.44 & 16 & 85.19 & 2 & Retention \\
\hline
\end{tabular}

Note: IDI = Item difficulty index

should be used when items have a large dispersion of item difficulty indexes, ranging from $10 \%$ to $90 \%$ (Sočan, 2011). In our results, this was true for both the pre-test and the posttest. With this method, the reliability was established by comparing two halves of a test that included items with similar difficulty indexes (see Sočan, 2011). For the pre-test, we calculated the split-half coefficient to be 0.615 , and for the post-test, the coefficient was 0.643. These values indicate low reliability of our test measures, but as mentioned before, larger samples are needed for calculation of the precise reliability coefficients (Charter, 2003).

\subsection{Data collection}

Experimental data were gathered from May 2017 till February 2018. We obtained ethical approval for the study from the Social Research Ethics Committee at UCC (SREC 2017028). The experiments took place in a laboratory in UCC. Four different persons conducted the experiments. Detailed written instructions were prepared on the procedure and on the verbal instructions to be issued so as to ensure the objectivity of the experimental procedure. Prior to conducting the study, each participant signed a consent form in accordance with the regulations of University College, Cork. By signing this form, they confirmed that they were informed about the nature of the study and their right to withdraw at any time. The experiment was run for each participant individually. The whole procedure took 30-45 minutes per participant. At the beginning, the participants were asked to answer an electronic version of the pre-test, which was undertaken on a laptop. Then, the participants were asked to move to a desktop computer to learn about web cookies from the multimedia instructions. They were informed that they had 12 minutes to learn but that they could finish earlier if they wanted to, and that they could navigate material freely during that time by scrolling the page or by using pause, play, forward, and rewind buttons in the video conditions. We introduced the time limit in order to minimise variations in learning resulting from variations 
in exposure time: allowing participants as much time as they wished might have led to large variations in time exposed to the learning material, and this would have represented a further variable. We performed several pilot trials in order to determine how much time was needed for students with dyslexia to read through the text or assimilate the video material. We informed participants that the time was limited, but assured them that they would have enough time to read/watch the content. In this way, we aimed to avoid causing anxiety. The imposition of a limit on the learning time can be seen in other studies (e.g., Höffler and Schwartz, 2011). During the learning task, participants were told at pre-determined intervals how much time they had left. Immediately after learning, they were asked to fill out an electronic version of the post-test.

\subsection{Data analysis}

Data were analysed, using the software program SPSS 25.0. For all variables, we calculated descriptive statistics: M, Mdn, SD, and coefficients of kurtosis and skewness. For testing the hypotheses, we applied non-parametric tests because of the very small number of participants in each group $(N=9)$. The Wilcoxon signed-rank test was applied to check if differences between pre- and post-test scores are significant within each of the groups. The Kruskal-Wallis test was applied to test for differences (in the pre-test, post-test scores and differences between pre- and post-test scores) between the three groups. It was also used for checking differences between groups in the control variables age and previous experience. The Kruskal-Wallis test is a non-parametric test used for examining the differences between more than two independent groups (Field, 2013). In addition, we also calculated the effect sizes $(r)$ for all non-parametric tests. Effect sizes were calculated using the following formula, acquired from Field (2013): $r=z / \sqrt{N} . z$ stands for standardized test statistics that SPSS produces for each test.

\section{Results}

We analysed three groups prior to and after learning. Prior to learning, we analysed the differences across groups in pre-test scores and controlling variables (age, and previous experience with managing cookies). After learning, we analysed the three groups on learning outcomes. Two learning outcomes were measured: post-test scores and the difference between post-test and pre-test scores. The post-test - pre-test difference indicated an increase or decrease in knowledge.

\subsection{Comparison of groups prior to learning}

First, we checked if the control group and two experimental groups differed in control variables. The three groups had equal numbers of male and female participants because the groups were matched on the variable of gender. In each group, there were four male and five female participants. The statistical analysis revealed no significant differences in the variable of age between the groups $(H=0.595 ; d f=2 ; p=0.743)$. There were also no significant differences in self-assessed previous experiences with managing cookies between the three groups $(H=0.546 ; d f=2 ; p=0.761)$. In the pre-test, the participants could score a maximum of 17 points. The median pre-test score for all participants was 8.00 , ranging from a minimum score of 2.00 points to a maximum score of 13.00 points. Table 2 presents the descriptive statistics for the pretest scores, separately for each group.

As indicated in Table 2, participants in the video lectures with subtitles group had the highest score on the pre-test $(\mathrm{Mdn}=9.00)$, followed by participants in the condition of 
Table 2: Descriptive statistics of pretest scores for different groups $(n=9)$

\begin{tabular}{lccc}
\hline & Website & Video lectures & $\begin{array}{c}\text { Video lectures } \\
\text { with subtitles }\end{array}$ \\
\hline M & 7.11 & 7.56 & 8.00 \\
SD & 2.09 & 2.79 & 2.78 \\
Mdn & 7.00 & 7.00 & 9.00 \\
Range & 6.00 & 9.00 & 9.00 \\
$\bar{R}$ & 12.56 & 13.33 & 16.11 \\
Skewness & -0.19 & 0.81 & -1.25 \\
Kurtosis & -1.34 & 0.45 & 2.02 \\
\hline
\end{tabular}

video lectures and website $(\mathrm{Mdn}=7.00)$. Differences in pre-test scores were not significant between the three groups $(H=1.017 ; d f=2 ; p=0.601)$.

\subsection{The comparison of groups after learning}

The results of the pre- and post-tests show an improvement in the scores of the majority (24) of the participants, meaning they achieved more points in the post-test than the pre-test. Two participants obtained post-test scores that did not improve from their pre-test, and one participant scored lower on the post-test than on the pre-test. It was discovered that for all of the three conditions, the increase in knowledge was significant from pre-test to post-test. In the website condition, the students' score on the post-test $(\mathrm{Mdn}=11.0)$ was significantly higher than the score on the pre-test $(\mathrm{Mdn}=7.00 ; T=34.00, p=0.023, r=0.54)$. The scores of students' learning in the video lectures condition improved significantly from pretest $(\mathrm{Mdn}=7.00)$ to post-test $(\mathrm{Mdn}=10.00 ; T=45.00, p=0.007, r=0.63)$. Additionally, for students learning from subtitled video lectures, the scores were significantly higher in the post-test $(\mathrm{Mdn}=11.00)$ than in pre-test $(\mathrm{Mdn}=8.00 ; T=36.00, p=0.011, r=0.60)$. All three conditions had a large effect $(r>0.50)$ on learning.

Further, we examined if the groups had different post-test results. Table 3 presents descriptive statistics for the post-test scores in each group. In the post-test, the participants could score a maximum of 17 points. In the total sample, the median pre-test score for all participants was 10.00 , ranging from a minimum score of 5.00 points to a maximum score of 15.00 points.

Table 3: Descriptive statistics of posttest scores for different groups $(n=9)$

\begin{tabular}{lrcc}
\hline & Website & Video lectures & $\begin{array}{c}\text { Video lectures } \\
\text { with subtitles }\end{array}$ \\
\hline M & 10.56 & 10.00 & 11.00 \\
SD & 2.10 & 2.18 & 2.12 \\
Mdn & 11.00 & 10.00 & 11.00 \\
Range & 8.00 & 8.00 & 7.00 \\
$\bar{R}$ & 15.00 & 11.78 & 15.22 \\
Skewness & -1.16 & 0.09 & 0.61 \\
Kurtosis & 1.03 & 1.72 & 0.35 \\
\hline
\end{tabular}

As seen in Table 3, the differences between groups in post-test scores were small. Participants learning from the website $(\mathrm{Mdn}=11.00)$ and the subtitled video lectures $(\mathrm{Mdn}=$ 
11.00) scored highest. However, there were no significant differences between groups, regarding their post-test results $(H=1.098, d f=2, p=0.578)$.

As the second measure of learning outcome, we examined pre-test-post-test differences across groups. We calculated the differences for each participant as the post-test score reduced by the pre-test score. The positive value of the difference implies an increase in knowledge and negative value, a decrease. The median value of improved scores was 3 points. The results are presented in Table 4.

Table 4: Descriptive statistics of pretest - posttest differences for different groups

\begin{tabular}{lccc}
\hline & Website & Video lectures & $\begin{array}{c}\text { Video lectures } \\
\text { with subtitles }\end{array}$ \\
\hline M & 3.44 & 2.44 & 3.00 \\
SD & 3.32 & 1.13 & 2.65 \\
Mdn & 5.00 & 2.00 & 3.00 \\
Range & 10.00 & 3.00 & 9.00 \\
$\bar{R}$ & 17.83 & 11.50 & 12.67 \\
Skew & -1.79 & 0.18 & 1.51 \\
Kurt & 2.73 & -1.17 & 3.15 \\
\hline
\end{tabular}

The students in the website condition showed the greatest difference between pre-test and post-test results $(\mathrm{Mdn}=5.00)$, while those in the video lecture condition showed the lowest difference $(\mathrm{Mdn}=2.00)$. The Kruskal-Wallis test on the differences across conditions showed that the enhancement of the scores did not significantly differ $(H=3.318$; $d f=2 ; p=0.190)$. It is evident from Table 4 that the range of pre- and post-test differences were much higher for website and video lecture with subtitles conditions than for the video lecture condition. The differences among the three groups are shown in Figure 1.

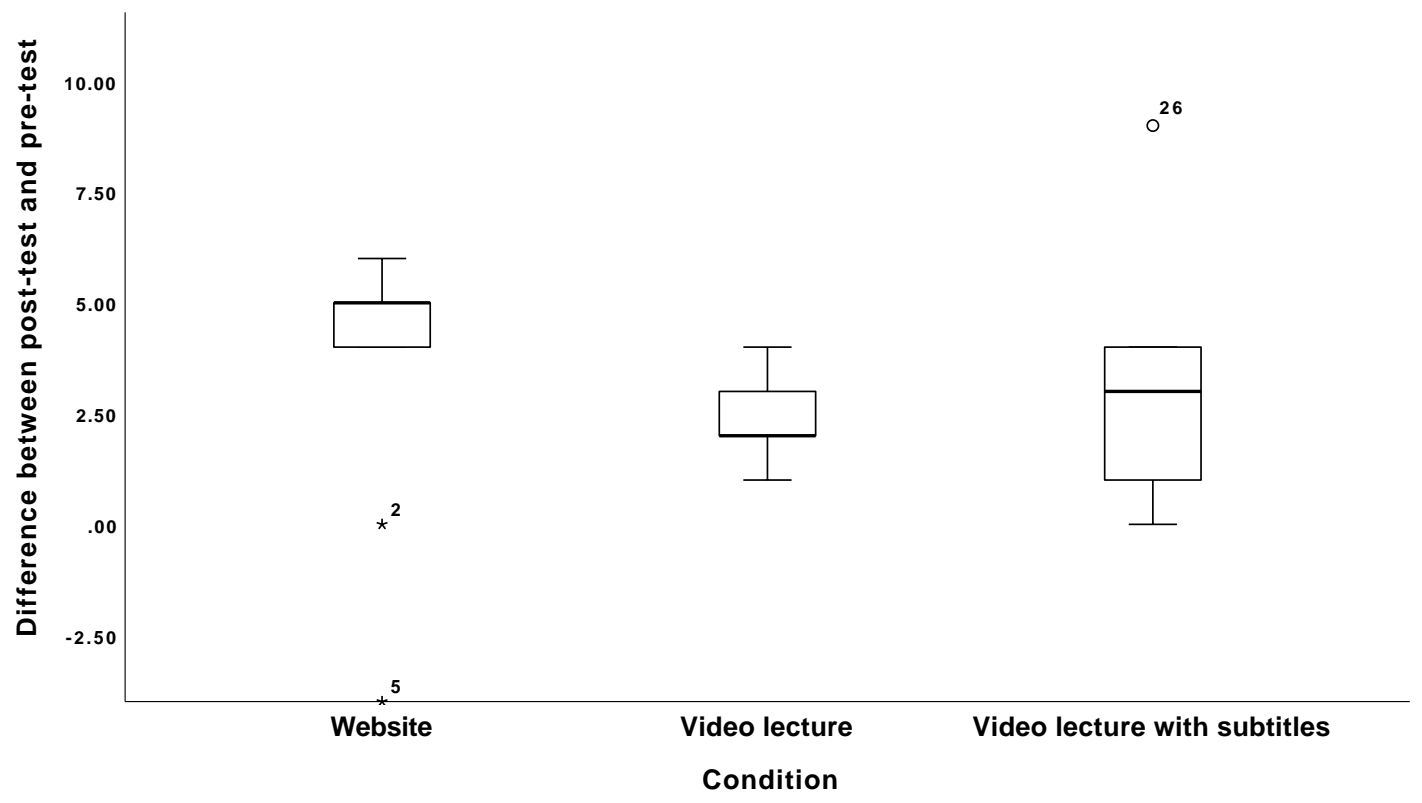

Figure 1: Boxplots of differences between post-test and pre-test across conditions

We calculated the effect sizes $(r$ ) for a focused comparison of the learning output mea- 
sures from the pairwise tests. In that way we calculated separate effect sizes for each pair of conditions (Field, 2013). Effect sizes are presented in Table 5.

Table 5: Effect sizes for comparisons of conditions

\begin{tabular}{lccccc}
\hline & \multicolumn{2}{c}{ Posttest } & & \multicolumn{2}{c}{ Difference } \\
\cline { 2 - 3 } \cline { 6 - 7 } Comparison & $z$ & $r$ & & $r$ \\
\hline Video lecture vs. Website & 0.88 & 0.21 & & 1.71 & 0.40 \\
Video lecture vs. Subtitled video lecture & -0.94 & -0.22 & & -0.32 & 0.07 \\
Subtitled video lecture vs. Website & -0.06 & -0.01 & & 1.40 & 0.33 \\
\hline
\end{tabular}

\section{Discussion}

The aim of our study was to discover the best multimedia combination for learning for students with dyslexia. We argue that in the case of digital learning content the more accessible content is probably related to more efficient learning. That is why we believe the most effective multimedia combination may be interpreted also as the most accessible content for students with dyslexia. We would like to highlight that because of the small sample, the results are not conclusive and need to be repeated with a larger sample.

In general hypothesis 1 and the specific hypotheses $2-4$, we assumed that learning from a certain multimedia combination will affect the learning outcomes. We assumed that the video lecture with subtitles would be the most effective multimedia combination for students with dyslexia, followed by the video lecture condition and that learning from the website would be the least effective option. In all groups, the difference between pre-test and post-test results was significant, meaning the participants in all the conditions showed more knowledge on the topic of web cookies after the learning occurred. Contrary to our expectation, no significant differences were found between groups in post-test scores or acquired knowledge (measured as the difference between pre-test and post-test), meaning that no condition was related to better learning outcomes. Therefore, we reject our general hypothesis (H1) and specific hypotheses (H2-H4) about the most optimal multimedia combinations for students with dyslexia.

Despite the fact that there were non-significant differences in learning outcomes between groups in three different conditions, the calculated effect sizes indicate some interesting findings. Learning in the website condition was found to have a medium effect $(r>0.30)$ on the increase in knowledge in comparison to the video lecture $(z=1.711 ; r=0.40)$ and the video lecture with subtitles $(z=1.396 ; r=0.33)$. All other comparisons yielded small effect sizes $(r<0.20)$. This indicates that learning from a website has a stronger effect on the knowledge gained than learning from a video lecture or a video lecture with subtitles.

If the modality principle of the CTML were valid when applied to the video condition, students would perform better in the video lecture than the website condition. Our results could indicate that the modality principle is not valid for students with dyslexia, which was also discovered in a study by Wang et al. (2018). Our results are also consistent with Beacham and Alty (2006), who found that neither of the provided multimedia combinations (onscreen text and picture versus narration and picture) was significantly effective for students with dyslexia. The most effective condition in their study was the text-only condition, and the worst was the multimedia combination of voice and picture, which indicate that the modality principle is not valid for students with dyslexia. However, rather than state that the 
CTML is not valid for students with dyslexia, our study indicates that for certain types of material (self-paced material, longer text), a reverse modality effect may appear for students with dyslexia, as it did for the mainstream population (Ginns, 2005; Reinwein, 2012; Tabbers et al., 2004; Wong et al., 2012). Especially, because the modality effect was discovered to be valid for children with dyslexia (Knoop-van Campen et al., 2019), there is also a possibility that university students as a population have developed some strategies that allow them to effectively learn from on-screen textual information if the textual information is provided in a self-paced form. Another possible explanation would be that students with dyslexia spend more time learning from on-screen textual information than from audio information in a video, which was the case in the study by Knoop-van Campen et al. (2019). In that case, more time spent on learning could contribute to diminished differences between website and video conditions. However, our study does not include an analysis of the learning time. Further, different types of visual content (not static pictures integrated with video) may result in a valid modality effect also for students with dyslexia. For example, She and Chen (2009) discovered that for mainstream students the modality effect was valid for animations, but not for simulations.

In our study, the video lecture condition was no better than the video lecture with subtitles condition, as we would expect it to be if the redundancy principle were valid. As the study by Liu et al. (2011) indicated, mainstream students, are able to ignore redundant information when doubled information is provided. Our results suggest that students with dyslexia are able to ignore redundant information, but this should be further researched. It is also possible that students with dyslexia simply ignored on-screen text, which could be examined with eye-tracking measures. Contrary to our expectations, we did not find any benefits in using subtitled video for students with dyslexia. As mentioned before, our results indicate that the video condition is not the most beneficial multimedia combination for students with dyslexia even if the material is self-paced as recommended for people with dyslexia.

No differences between different multimedia conditions could mean that the modality and redundancy principles of CTML are not valid for higher education students with dyslexia, but could also mean that CTML principles are not easily applicable to video lectures. It should also be highlighted that CTML principles are more related to deep learning outcomes, such as learning transfer (Knoop-van Campen et al., 2019), while our test mostly measured retention.

Despite students with dyslexia having problems with reading, our results indicate that video material may be less accessible to students with dyslexia than static scroll-down websites. Although our study should be repeated with a larger number of participants to determine whether the differences are indeed significant, the results warrant further research on the accessibility of videos for students with dyslexia.

However, in our study, the assessment was mostly related to factual knowledge and not to procedural knowledge. Previous studies focused on videos aimed at improving skills, for example, in software use (van der Meij and van der Meij, 2014) or cooking (Surgenor et al., 2017).

Another interesting finding in our study was the variety of learning outcomes in two out of three conditions. The pre-test-post-test difference for the website was 10.00 points, and for the video lectures with subtitles condition, it was 9.00 points. In the website condition, the majority of the participants scored higher on post-test than pre-test, but one person in the website condition did not show an improvement in the score and one person showed less knowledge in post-test. In the video lecture with subtitles, one person scored the same in preand post-test. In the video lecture, all participants improved their knowledge in the range of 
3.00 points. This indicates the presence of individual differences and leads to questions on the effectiveness of the two multimedia combinations (website, video lecture with subtitles) for certain individuals. In this case, relevant individual characteristics (e.g., learning styles) should be explored in the future. However, because of our small sample, we cannot draw any conclusions on the issue.

\section{Conclusions and future directions}

In the higher education landscape where multimedia learning materials are widely used, institutions, teachers and students need greater awareness of what makes learning material optimal and accessible. Multimedia learning theory has strong empirical support; however, it lacks the validity of CTML principles (e.g., redundancy principle, modality principle) for students with dyslexia. In our study, we aimed to identify the most accessible type of digital learning material for students with dyslexia. Studies show that students with dyslexia, have preferences for video materials (Webster, 2016) and are frequent users of video lectures (Leadbeater et al., 2013). We expected that students would learn best from a subtitled video lecture as this condition supports a multisensory approach. We also expected that the students would perform the least well in the website condition as on-screen text would present difficulties for them because students with dyslexia have evident difficulties with reading. Our results did not support our hypothesis. There were no significant differences in post-test results in knowledge gained between the three conditions. However, the calculated effect sizes indicate that learning in the website condition had a stronger effect on learning outcomes (post-test results) than learning in the other two conditions. The main limitation of our study is the small sample size. This is a commonly-encountered problem in studies involving learners with special needs and other special populations. For example, a study by Alty et al. (2006) also included 30 students with dyslexia, 10 in each of the conditions.

Even though we tried to control many confounding variables (by matching on gender, not including IT students, including only students who met the criteria used by UCC to identify students with dyslexia in need of support, using very similar material in all three conditions, making equal time available for learning), the small sample size does not allow us to suggest any conclusive findings. In view of the findings, we would suggest that it be repeated in future on larger samples. This is particularly important because our results are to some extent aligned with those obtained from other studies on students with dyslexia learning from multimedia in which the sample size was also relatively small (Alty et al., 2006, Wang et al., 2018). In the future, qualitative measures should be incorporated in the research design (e.g., interviews on the learning experience in different multimedia combination) as this would provide additional value, especially because studies involving special educational needs students are often, as stated before, conducted on small samples. Our study opens up questions about the accessibility of video material for students with dyslexia. The use of video in higher education is recognised, and institutions and teachers should be aware of providing optimal conditions for learning (Colliot and Jamet, 2018) for diverse student groups. Accessible learning content is required in order to reduce the danger of students becoming disadvantaged in their studies (Kumar and Owston, 2016). Further researches are needed to establish the limits and conditions of video use for students with dyslexia. With the more and more pervasive use of video in online environments, including in the context of formal HE environments, the issue definitely needs further attention. 


\section{Acknowledgements}

The study was financed by the young researcher scheme of the Slovenian Research Agency (ARRS) for acquiring a $\mathrm{PhD}$ as a part of $\mathrm{PhD}$ study. Andreja Istenič Starčič was nominated as a mentor of a young researcher in 2011 (6316-3/2011-784) and her work also is financially supported by Slovenian Research Agency (P2-0210). Maja Lebeničnik was selected as a young researcher in 2012 (No. 2158) The Social Research Ethics Committee (SREC) at University College Cork approved the study on 12th April 2017. The reference is SREC 2017-028.

\section{References}

[1] Abd Ghani, K. and Gathercole, S.E. (2013): Working memory and study skills: A comparison between dyslexic and non-dyslexic adult learners. Procedia - Social and Behavioral Sciences, 97, 271-277.

[2] Alty, J.L., Al-Sharrah, A., and Beacham, N. (2006): When humans form media and media form humans: An experimental study examining the effects different digital media have on the learning outcomes of students who have different learning styles. Interacting with Computers, 18, 891-909.

[3] Asuncion, J.V., Budd, J., Fichten, C.S., Nguyen, M.N., Barile, M., and Amsel, R. (2012): Social media use by students with disabilities. Academic Exchange Quarterly, 16(1), 30-35.

[4] Beacham, N. and Alty, J. (2006): An investigation into the effects that digital media can have on the learning outcomes of individuals who have dyslexia. Computers \& Education, 47, 74-93.

[5] Bell, L. (2009): Web accessibility: Designing for dyslexia. http://lindseybell. com/documents/bell_dyslexia.pdf Retrieved 20.3.2014.

[6] Björklund, M. (2011): Dyslexic students: Success factors for support in a learning environment. The Journal of Academic Librarianship, 37(5), 423-429.

[7] Boyle, J.R. (2012): Note-taking and secondary students with learning disabilities: Challenges and solutions. Learning Disabilities Research \& Practice, 27(2), 90-101.

[8] Charter, R.A. (2003): Study samples are too small to produce sufficiently precise reliability coefficients. The Journal of General Psychology, 130(2), 117-129.

[9] Cullen, R. (2001): Addressing the digital divide. Online Information Review, 25(5), 311-320.

[10] Colliot, T. and Jamet, E. (2018): Understanding the effects of a teacher video on learning from a multimedia document: An eye-tracking study. Education Technology Research and Development, 66, 1415-1433.

[11] Dewan, M. and Spindel, E. (2015): Social Media Accessibility. http://thesierragroup.com/assets/documents/ 12-10-15SocialMediaAccessibilityArticle_with\%20_bylines_tagged.pdf Retrieved 31.1.2018. 
[12] Draffan, E.A. (2002): Dyslexia and technology. In L. Phipps, A. Sutherland and J. Seale (eds.): Access all areas: Disability, technology and learning, 24-28. JISC TechDis.

[13] Field, A. (2013): Discovering statistics using IBM SPSS Statistics. London: Sage.

[14] Giardi, A. (2016): Engage students with dyslexia in video-based learning activities. Journal of Safety Science and Technology, 1, 15-35.

[15] Ginns, P. (2005): Meta-analysis of the modality effect. Learning and Instruction, 15, 313-331.

[16] Greer, D.L., Crutchfield, S.A., and Woods, K.L. (2013): Cognitive theory of multimedia learning, instructional design principles, and students with learning disabilities in computer-based and online learning environments. Journal of Education, 193(2), $41-50$.

[17] Gyselinck, V., Jamet, E., and Dubois, V. (2008): The role of working memory components in multimedia comprehension. Applied Cognitive Psychology, 22, 353-374.

[18] Habib, L., Berget, G., Sandnes, F.E., Sanderson, N., Kahn, P., Fagernes, S., and Olcay, A. (2012): Dyslexic students in higher education and virtual learning environments: An exploratory study. Journal of Computer Assisted Learning, 28(6), 574-584.

[19] Höffler, T.N. and Schwartz, R.N. (2011): Effects of pacing and cognitive style across dynamic and non-dynamic representations. Computers \& Education, 57, 1716-1726.

[20] Knoop-van Campen, C. A., Segers, E., and Verhoeven, L. (2019): Modality and redundancy effects, and their relation to executive functioning in children with dyslexia. Research in Developmental Disabilities, 90, 41-50.

[21] Kumar K.L. and Owston, R. (2016): Evaluating e-learning accessibility by automated and student-centered methods. Education Technology Research and Development, 64, 263-283.

[22] Leadbeater, W., Shuttleworth, T., Couperthawaite, J., and Nightingale, K.P. (2013): Evaluating the use and impact of lecture recording in undergraduates: Evidence for distinct approaches by different groups of students. Computers \& Education, 61, 185192.

[23] Liu, H-C., Lai, M-L., and Chuang, H-H. (2011): Using eye-tracking technology to investigate the redundant effect of multimedia web pages on viewers' cognitive processes. Computers in Human Behavior, 27, 2410-2417.

[24] Mayer, R.E. (2003): The promise of multimedia learning: Using the same instructional design methods across different media. Learning and Instruction, 13, 125-139.

[25] Mayer, R.E. (2009): Multimedia learning. New York, NY: Cambridge University Press.

[26] McCarthy, J. E. and Swierenga, S.J. (2010): What we know about dyslexia and Web accessibility: A research review. Universal Access in the Information Society, 9(2), $147-152$. 
[27] McDowell, J. and Catterall, S. (2014): Using asynchronous video to enhance engagement with learning, assessment and feedback for learners affected by dyslexia. In: Proceedings of the Second international conference on the use of new technologies for inclusive learning.

[28] Mortimore, T. and Crozier, W.R. (2006): Dyslexia and difficulties with study skills in higher education. Studies in Higher Education, 31, 235-251.

[29] Olofsson, A., Ahl, A., and Taube, K. (2012): Learning and study strategies in university students with dyslexia: Implications for teaching. Procedia - Social and Behavioral Sciences, 47, 1184-1193.

[30] Ramus, F., Rosen, S., Dakin, S.C., Day, B.L., Castellote, J.M., White, S., and Frith, U. (2003): Theories of developmental dyslexia: Insights from a multiple case study of dyslexic adults. Brain, 126, 841-865.

[31] Ravanelli, F. and Serina, I. (2014): Didactic and pedagogical view of e-learning activities Procedia - Social and Behavioral Sciences, 116, 1774-1784.

[32] Reid, G., Strnadova, I., and Cumming, T. (2013): Expanding horizons for students with dyslexia in the 21st century: Universal design and mobile technology. Journal of Research in Special Educational Needs, 13(3), 175-181.

[33] Reinwein, J. (2012): Does the modality effect exist? And if so, which modality effect? Journal of Psycholinguistic Research, 41, 1-32.

[34] Rose, J. (2009): Identifying and teaching children and young people with dyslexia and literacy difficulties: An independent report from Sir Jim Rose to the Secretary of State for Children, Schools and Families. Department for Children, Schools and Families.

[35] Ruedas-Rama, M.J. and Orte, A. (2012): Using text-to-speech generated audio files for learning chemistry in higher education. International Journal of Physics \& Chemistry Education, 4(1), 65-77.

[36] Rummer, R., Schweppe, J., Fürstenberg, A., Scheiter, K., and Zindler, A. (2011): The perceptual basis of the modality effect in multimedia learning. Journal of Experimental Psychology: Applied, 17(2), 159-173.

[37] Santana, F.V., de Oliveira, R., Anhol Almeida L., and Calani Baranauskas, M.C. (2012): Web accessibility and people with dyslexia: A survey on techniques and guidelines. Proceedings of the International Cross-Disciplinary Conference on Web Accessibility, April 16-17, Lyon, France.

[38] She, H.C. and Chen, Y.Z. (2009): The impact of multimedia effect on science learning: Evidence from eye movements. Computers \& Education, 53(4), 1297-1307.

[39] Sorden, S.D. (2013): The cognitive theory of multimedia learning. In B. Irby, G. Brown, Lara-Alecio, R. and Jackson, S. (eds.): The handbook of educational theories. Charlotte: Information Age Publishing.

[40] Sočan, G. (2011): Postopki klasične testne teorije. Ljubljana: Filozofska fakulteta. 
[41] Surgenor, D., Hollywood, L., Furey, S., Lavelle, F., McGowan, L., Spence, M., Raats, M., McCloat, A., Mooney, E., Caraher, M., and Dean, M. (2017): The impact of video technology on learning: A cooking skills experiment. Appetite, 114, 306-312.

[42] Tabbers, H.K., Martens, R.L., and van Merrienboer, J.J.G. (2004): Multimedia instructions and cognitive load theory: Effects of modality and cueing. British Journal of Educational Psychology, 74, 71-81.

[43] Taylor, M., Duffy, S., and Hughes, G. (2007): The use of animation in higher education teaching to support students with dyslexia. Education + Training, 49(1), 25-35.

[44] Thambirajah, M.S. (2010): Developmental dyslexia: An overview. Advances in Psychiatric Treatment, 16, 299-307.

[45] van der Meij, H. and van der Meij, J. (2014): A comparison of paper-based and video tutorials for software learning. Computers \& Education, 78, 150-159.

[46] Vellutino, F.R., Fletcher, J.M., Snowling, M.L., and Scanlon, D.M. (2004): Specific reading disability (dyslexia): What have we learned in the past four decades? Journal of Child Psychology and Psychiatry, 45(1), 2-40.

[47] Vrhovski, M. (2007): Vključevanje študentov s posebnimi potrebami v visokošolsko izobraževanje. Šolsko polje, 3/4, 109-132.

[48] Wang, J., Dawson, K., Saunders, K., Ritzhaupt, A.D., Antonenko, P.P., Lombardino, L., ... Davis, R.O. (2018): Investigating the effects of modality and multimedia on the learning performance of college students with dyslexia. Journal of Special Education Technology, 33(3), 182-193.

[49] Web Accessibility Initiative (2005): Introduction to web accessibility. http://www . w3.org/WAI/intro/accessibility.php Retrieved 19.9.2014.

[50] Web Accessibility Initiative (2017): Diversity of web users. http://www.w3.org/ WAI/intro/people-use-web/diversity.html Retrieved 6.2.2018.

[51] Webster, D.M. (2016): Listening to the voice of dyslexic students at a small, vocational higher education institution to promote successful inclusive practice in the 21 st century. International Journal of Learning and Teaching, 2(1), 78-86.

[52] Wong, A., Leahy, W., Marcus, N., and Sweller, J. (2012): Cognitive load theory, the transient information effect and e-learning. Learning and Instruction, 22, 449-457.

[53] Woodfine, B.P., Baptista Nunes, M., and Wright, D.J. (2008): Text-based synchronous e-learning and dyslexia: Not necessarily the perfect match! Computers \& Education, 50, 703-717.

[54] Yurdugül, H. (2008): Minimum sample size for Cronbach's coefficient alpha: A Monte-Carlo study. Journal of Education, 35, 397-405. 